The Jolly Electron.

Sung to the Tune of "The Jolly Miller," at the Physical Society Club.

I. There was a jolly electron-alternately bound and free-

Who toiled and spun from morn to night, no Snark so lithe as he;

And this the burden of his song for ever used to be:-

"I care for nobody, no, not I, since nobody cares for me."

\section{Chorus.}

And this the burden of his song for ever used to be,

"I care for nobody, no, not I, since nobody cares for me."

2. Though Crookes at first suspected my presence on this earth,

'Twas J. J. Thomson found me--in spite of my tiny girth.

He measured first the "e by $m$ " of my electric worth ;

I love J. J. in a filial way, for he it was gave me birth!

Chorus.

But this the burden of my song, etc.

3. 'Twas Johnstone Stoney invented my new electric name,

Then Rutherford, and Bohr, too, and Moseley brought me fame;
They guessed (within the atom) my inner and outer game,

You'll all agree what they did for me,

I'll do it for them, the same!

Chorus.

But this the burden of my song, etc.

4. Then Wilson, known as 'C. T. R.,' his camera brought to bear,

And snapped me (and the Alphas too) by fog-tracks in the air.

We like that chap! For a camera snap is a proof beyond compare ;

A regular star is C. T. R., we'd follow him anywhere! Chorus.

But this the burden of my song, etc.

5. So whether I rest as static charge, or rove in the ether free,

Or whether I settle in nuclear state, perched up on a proton's knee,

Or whether I spin my quantum yarns, in a spectroscopic key,

I'll love the 'Physicals' all the time, since all of 'em dote on me.'

\section{Chorus.}

But this the burden of my song for ever used to be,

"I care for nobody, no, not I, since nobody cares for me."

\title{
The Cavendish Laboratory as a Factor in a Counter-Revolution.
}

\section{Sir NAPIER SHAW, F.R.S.}

$\mathrm{N}^{\mathrm{o}}$ OW that Parliament in its wisdom has once more made the University of Cambridge responsible for the teaching of its students, the wheel has come round full circle and we may fairly indulge in a retrospect about the teaching of science. The story may begin with $185 \mathrm{I}$, when reforms were introduced largely at the instance of the Prince Consort, who had been elected Chancellor in 1847 . There is an early pencilling in Punch, by John Leech, representing the election day with a placard of the opposition "Boats no Botany." It is astonishing how placidly an undergraduate can go through his course unconscious of living in a time of momentous change. The final statutes for the University of the $185 \mathrm{I}$ Commission are dated $185^{8}$; but for the first time, in $185^{1}$, the class lists record the results of a Moral Sciences Tripos and a Natural Sciences Tripos, both quite new. Previously, dating back to I 824 , there had been a Classical Tripos; but before $185 \mathrm{I}$ it was limited to candidates who had already obtained honours in the Mathematical Tripos. The published class lists of that educational instrument go back to $1747-48$ and form the connecting link between the triposes of to-day and the academic system of the Middle Ages when the University was paramount.

In my undergraduate days there were still some notable relics of that system. Within the structure of the central University building, the Library, there were a Divinity School, a Law School, and an Arts School, each arranged like a court of justice. There was a Medical School also ; but already it possessed a separate building with a museum and dissectingroom.

The schools were originally arranged for the candidates for honours to ' keep' their 'acts' for degrees in the faculties of Divinity, Law, Arts, and Medicine, with moderators for judges, proctors for police, and University students for the general public. The candidate sat upon his tripos. as proponent of a thesis in theology, law, medicine, or philosophy, with opponents to take sides in a public disputation. That had been the medieval plan for deciding upon the relative merits of the candidates. Since the beginning of the sixteenth century there had been. Regius professors in divinity, law, and physic, who could act as moderators for their faculties. There was also a Regius professor of Greek who might have been regarded as dean of the general faculty of arts or philosophy ; but the colleges had captured the right of moderation in that faculty before the end of Queen Elizabeth's reign, and moderators were nominated by the colleges in turn, according to a fixed rota.

The colleges had also assumed responsibility for the education of their students in preparation for the final NO. $298 \mathrm{I}$, VOL. I I 8 ] 
act. The University had only to decide the relative merits of the candidates from different colleges. It accepted for matriculation, without examination, the candidates presented by a representative of a college in person. The colleges had their own curricula and provided their own teaching upon which they based their right to certify candidates as worthy of degrees.

The college curriculum was still in vogue in my time ; it consisted of lectures on classical and mathematical subjects which were combined in one annual examination upon the results of which prizes were awarded. The subjects were in fact selected with an eye to the University examinations, which at that time and developed into a system. Physical science formed no part, except in so far as physical subjects were included in the comprehensive subject of mathematics.

It must be remembered that what was called mathematics in the third quarter of the nineteenth century was the direct successor of the arts or natural philosophy of the schoolmen. Latin was the language of the arts, and the colleges taught Latin. There was no professorship of Latin in the University until 1869. From 1663 there was a Lucasian professor of natural philosophy. Isaac Barrow was the first, Newton the second. From I680 there was a professor of moral philosophy. Before the end of the eighteenth century there were in addition two professors of astronomy, professors of chemistry, modern history, Arabic, botany, geology, and natural and experimental philosophy, all of whom may have looked to the curriculum in arts for their students.

With the development of mathematics after Newton, 'arts' became concentrated in natural philosophy. The Act in the schools gave insufficient scope for adequate testing and a written examination was instituted, which carried off the name of the tripos and became the Mathematical Tripos ; but when I was introduced to it its range was by no means restricted. It included statics, dynamics, hydrostatics, optics (geometrical and physical), spherical astronomy, lunar and planetary theories, hydrodynamics, sound, waves and tides, elasticity, heat, electricity, and magnetism. The last three were in a sense new; the University had restored the original comprehensive range of natural philosophy by adding them as additional subjects, and appointed an additional examiner for them. James Clerk Maxwell was the first.

Thus the range was very wide; but the teaching was not coterminous with the subjects named. From the nature of the examination, it became limited to the mathematical extracts from the original contributions of accepted authorities. There were, in fact, in the colleges some survivals of an experimental method in the shape of an unused skeleton or the residue of an Atwood's machine; but the philosophy and history of the sciences were disregarded. I remember an example. We had to be examined in thermodynamics. P. G. Tait had written a book about it. Tait was a first-class talker and disputant; his book has three chapters ; the first two were interesting and polemic, the third was thumb-nail mathematics. We were instructed to confine our attention to the third-to ' cut the cackle' and come to the differential equations.
Thereby I am reminded that in the period from $\mathrm{I}_{86}$ until 1875 there was an effervescence of text-books in pure and applied mathematics, the like of which can never have been seen before or since. They were mostly bound in green, and judging from the survivals in my own library, the firm of Messrs. Macmillan and Co. must have been mainly responsible for the output. It was also a period of the greatest exaltation of the private tutor, in connexion with which the names of Hopkins and Routh will be remembered. Routh had an astonishing faculty for enabling pupils to absorb the mathematical juice of the great crop of text-books, so that the amount of information appropriated in the course of three years is now almost beyond belief. To those of us who had some experience of practical physics and chemistry at school or at home it was an invaluable discipline. What it could mean to those who had not, I cannot guess.

Then came Nemesis. The University, or somebody else, realised that all this tremendous appropriation of the mathematical secretions of the workers in natural philosophy without any experiment was not exactly healthy. There was indeed a chemical laboratory, and the Lucasian professor at the time was an experimentalist, so was the Jacksonian professor; but practical astronomy in my experience was one visit to the Observatory to be shown the adjustments of the transit instrument and the mural circle--we might be asked about those in the tripos, but not about stars.

The new idea of restoring the experimental study of natural philosophy found expression by the Duke of Devonshire, Chancellor of the University, in the foundation of the Cavendish Laboratory. Michael Foster had been brought to Cambridge by Trinity College about the same time as prælector in physiology, and a laboratory was found for him somewhere.

The early days of the Cavendish Laboratory were of peculiar interest. People who have since distinguished themselves worked there at their leisure: George Chrystal, Sir Donald MacAlister, W. M. Hicks, Sir Arthur Schuster, and Sir Richard Glazebrook. There were lectures by the professor and more elementary lectures by his demonstrator, W. Garnett; but there were no practical ' classes,' though the Natural Sciences 'Tripos included a practical examination. So the last quarter of the nineteenth century may indeed be aptly called the age of the practical class in science. Any one who visited the University now would scarcely suppose it possible that fifty years ago there were no classes in practical work.

It may perhaps be said now that there are too many; and indeed it is scarcely an exaggeration to write that the only thing to do with any system of education that has become established is to change it. No plan can be permanently successful; at least no scheme of examination can be.

Sir Richard Glazebrook and I made a text-book and, as we thought, a very good one. It was designed to enable a class of students to inform themselves about the physical nature of things by using different aggregations of the miscellaneous collection of apparatus at the Laboratory.

I sometimes wonder how many of those experiments we had ourselves performed when we described them

$$
\text { NO. 298I, VOL. II } 8 \text { ] }
$$


in such detail. But with the examination before them, our students and their successors have insisted on doing them all, and perhaps from their point of view they were right; but the result is wrong. The experiments were designed and described as a short cut to something better.

Nevertheless, the practical work in science, of which the Cavendish Laboratory is typical, furnished demon- strations not only of experimental physics but also of the University's care for teaching. The example has been followed, expanded, and improved until this term, under the new statutes, the University has recaptured from the colleges the right to teach its students the arts, as well as divinity, law, and medicine, a right which it surrendered in the spacious days of Queen Elizabeth.

\section{News and Views.}

Photographs of the 'Pithecanthropus skull' recently obtained at Trinil in Java by Dr. Heberlein have now been received by Dr. Dubois of Haarlem. At the time of the discovery it was positively announced to be of the pithecanthropus type; but Prof. Elliot Smith has received a cablegram from Dr. Dubois in which he says, "Photographs received show caput humeri stegodon." The second pithecanthropus skull thus turns out to be a pleistocene elephant! Much disappointment will be felt at this pronouncement, which, however, does not come entirely as a surprise. The information received in England from America soon after the first announcement made it clear that the discovery was not likely to prove so important as at first indicated. The more complete statement of the character of the find and the conditions in which it was obtained-it was not found in situ as at first stated, but was obtained from the inhabitants of the village, and it was also said not to be a complete skull-pointed to the need for suspending judgment on the importance of the find. The wide publicity given to the discovery serves to emphasise the dangers of over-hasty dissemination of news through the ordinary channels of the press without effective and well-informed supervision such as might be afforded through the medium of a centralised scientific news service.

The Right Hon. Neville Chamberlain, Minister of Health, presided at the reopening ceremony of the Wellcome Bureau of Scientific Research and the Museum of Medical Science on December 8. In the unavoidable absence abroad of the founder, Mr. Wellcome, Dr. C. M. Wenyon, Director of the Bureau, received the guests. Mr. Chamberlain, in the course of his remarks, dwelt on the great advances made by medical science in the course of the last century, largely due, in his opinion, to the improvement in the means of imparting knowledge to those interested throughout the world. $\mathrm{He}$ considered that the motive actuating Mr. Wellcome in founding the Bureau was a conception of the two greatest factors which help mankind to overcome the infirmities to which all, in some degree or other, are subject; these two factors are research and education. Research is carried on not only at the Bureau, but also at the Wellcome Physiological and Chemical Research Laboratories; education is subserved by the Museum of Medical Science, to which all interested are welcomed, where, moreover, teachers are permitted to give demonstrations to their students.

Sir Walter Fletcher, Secretary of the Medical Research Council, followed Mr. Chamberlain with an

$$
\text { NO. 298I, VOL. II } 8 \text { ] }
$$

address on "Research and Citizenship." After referring to the admirable scientific work of the staff of the Bureau, he turned to the consideration of the means by which research has been in the past and is at present financed. Many brilliant investigators have been enabled to pursue their work owing to the accident of possessing private means or owing to the liberality of some friend or private institution. It is only within the last twenty-five years that the State has made grants in aid of research work, with the establishment of such institutions as the National Physical Laboratory in 1900 and the Medical Research Council (then a Committee) in I913. Business firms have forwarded scientific work in three ways. Private fortunes made in commerce have been devoted to the endowment of research. Manufacturing firms have set up their own research laboratories; and although the investigators are not always free to publish the results of their work, yet the public are indirectly benefited by the increased efficiency of the firms in question. Finally, a few firms have adopted the plan of setting up research laboratories and leaving the workers as free to follow their own line and publish their results as men in any university laboratory. In Great Britain, the Wellcome Bureau is an example of the latter method of endowing research; abroad, the work of Langmuir and Coolidge in America and of Sørensen in Copenhagen has been made possible by similar endowments from commercial firms. The proceedings were terminated by Mr. Chamberlain declaring the Bureau and Museum open, and the guests then accompanied him and Dr. Wenyon on a tour of the halls and laboratories.

IN an address on "International Interests in Raw Materials" to the Royal Society of Arts, which is published in the Society's Journal for November 26, Sir Thomas Holland laid stress on the importance, for economic as well as military reasons, of making a precise estimate of the mineral resources of the British Empire. A large number of minerals are essential for the maintenance of civilisation, and many of them cannot be replaced in the functions for which they are used. Minerals are wasting assets, and their consumption is annually accelerating to such an extent that a partial famine for some important substances will confront the next generation. The United States has recently inaugurated a systematic inquiry into its stocks of essential minerals on lines of precision and thoroughness that will leave little doubt as to resources available. For the British Empire the matter is at least of equal importance. The Mineral Resources Bureau collects 